\title{
ANALISIS KESENJANGAN ANTARA EKSPEKTASI KONSUMEN TERHADAP PERSEPSI JASA PELAYANAN \\ (Studi Kasus pada Bengkel Cat dan Las Mobil Warna Indah di Kediri)
}

\author{
Gandung Satriyono \\ Universitas Kadiri - Kota Kediri \\ gandungsatriyono@unik-kediri.ac.id \\ M. Dian Ruhamak \\ Universitas Kadiri - Kota Kediri \\ dianru@unik-kediri.ac.id
}

\begin{abstract}
In the early survey, the researcher got the features of Warna Indah Car Workshop in not only claimed to give good service but also be able to compete for its survival by giving the best service quality. The purpose of this research is to prove whether any differentiate between perception and expectation from customers toward the service quality dimension at Warna Indah Car Color and Weld Workshop in Kediri which including tangibles, reliability, responsiveness, assurance, and empathy. This research used cross sectional method and the variable was measured once. The population of the research was customers of Warna Indah Car Color and Weld Workshop in Kediri. The data collected used interview, observation, and questionnaire. Based on the calculation of product moment correlation by using software SPSS V22, it was gotten, there was a a gap for each service quality and the highest gap was service quality dimension of $T 1$ indicator ( the location of Warna Indah Workshop), it was analyze by using Kartesius diagram in quadrant B with the low priority -0.15, the average value of service quality ( perception) 3.8125 and service hope (expectation) 3.9625 .
\end{abstract}

Keywords : differentiate, service quality, Tangibles, Reliability, Responsiveness, Assurance, Empathy

\begin{abstract}
Abstrak
Tujuan dari penelitian ini adalah untuk membuktikan apakah terdapat kesenjangan antara persepsi dan ekspetasi konsumen terhadap dimensi kualitas pelayanan yang ada di Bengkel Las dan Cat Warna Indah yang meliputi Tangibles, Reliability, Responsiveness, Assurance dan Empathy. Target khusus dalam penelitian ini adalah dimensi kualitas pelayanan manakah yang menjadi prioritas utama untuk diperbaiki agar kesenjangan konsumen dapat di atasi. Penelitian ini menggunakan metode cross sectional, dimana variabel penelitian diukur sekali saja. Adapun populasi dalam penelitian ini adalah pelanggan pengguna jasa Bengkel Las Dan Cat Mobil Warna Indah Di Kediri. Teknik pengumpulan data memakai interview, observasi dan kuisioner. Dengan adanya penelitian ini diharapkan mampu mengetahui kesenjangan konsumen pada Bengkel Las Dan Cat Warna Indah agar kesenjangan tersebut dapat diatasi serta ke depannya kualitas layanan pada Bengkel Cat Warna
\end{abstract}


Indah dapat lebih ditingkatkan sehingga konsumen merasa puas dan kesenjangan tidak muncul di kemudian hari.

Kata Kunci : Kesenjangan, Kualitas Pelayanan, Bukti Fisik, kemmpuan, daya tanggap, jaminan, perhatian.

\section{PENDAHULUAN}

Sejalan dengan persaingan yang semkin ketat, maka Bengkel Cat dan Las Mobil Warna Indah Kediri perlu melakukan berbagai usaha untuk mempertahankan konsumen dan mengantisipasi adanya kemungkinan konsumen pindah ke bengkel lain serta meraih konsumen yang baru. Oleh karena itu, mengetahui harapan pelanggan sangat penting bagi perusahaan. Kepuasan akan tercapai apabila perusahaan mampu memberikan kualitas pelayanan sesuai dengan harapan konsumen. Untuk menilai kualitas pelayanan, para ahli pemasaran seperti Parasuraman, Zeithaml, Berry (Tjiptono, 2001) telah mengajukan 5 faktor yang digunakan dalam menilai kualitas jasa, yaitu tangible, reliability, responsiveness, assurance, emphaty.

Tujuan dari penelitian ini adalah untuk membuktikan adanya kesenjangan antara persepsi dan ekspetasi konsumen terhadap dimensi kualitas pelayanan yang ada di Bengkel Las dan Cat Warna Indah yang meliputi Tangibles, Reliability, Responsiveness, Assurance dan Empathy.

\section{METODE PENELITIAN}

Populasi yang menjadi objek penelitian adalah para pengguna jasa bengkel mobil Warna Indah di Kediri. Sampel yang diteliti diambil dengan teknik Systematic Random Sampling (Supriyanto \& Djohan, 2011). Sampel penelitian berjumlah 80 orang.

\section{Analisa Data Servqual}

Kuisioner yang telah ditetapkan ukuran sampel dengan menggunakan rumus slovin dan disebarkan pada responden atau konsumen yang mendapat pelayanan di Bengkel Warna Indah diberikan skor nilai berdasarkan skala Likert dengan skala pengukuran 1-5 dengan penjabaran sebagai berikut :

STP = sangat tidak puas (skor 1 )

$\mathrm{TP} \quad=$ tidak puas $($ skor 2$)$ 
$\mathrm{C}=$ cukup puas (skor 3$)$

$\mathrm{P} \quad=$ puas $($ skor 4$)$

$\mathrm{SP} \quad=$ sangat puas (skor 5)

(Arikunto, Suharsimi. 1998)

Setelah dinyatakan valid dan reliable selanjutnya dicari nilai rata-rata masingmasing variabel dimensi yang diteliti dari setiap indikator tiap kuisioner kemudian dianalisis dengan menggunakan Diagram Kartesius yaitu Untuk mendapatkan gambaran apa yang harus diperbuat untuk diperbaiki keadaan variable-variabel dimensi kualitas layanan dan analisis SPSS 16 untuk mengetahui adanya kesenjangan antara ekspektasi konsumen terhadap persepsi jasa pelayanan pada Bengkel Warna Indah di Kediri. Lima dimensi yang menjadi acuan pengukuran yang di lakukan Customer terhadap pelayanan yaitu (Yamit, Zulian. 2002.)

1. Reliability, Kemampuan memiliki performa yang bisa di andalan dan akurat.

2. Assurance, Kemampuan para personel untuk menimbulkan rasa percaya dan aman kepada pelanggan.

3. Tangibles, Aspek yang terlihat secara fisik masalah peralatan dan personel petugas.

4. Empathy, Mencakup kepedulian serta perhatian individual kepada para pengguna.

5. Responsiveness, yaitu kesediaan untuk membantu partisipan dan memberikan perhatian yang tepat. 


\section{Alir Penelitian}

\section{Gambar 1. Alir Penelitian}

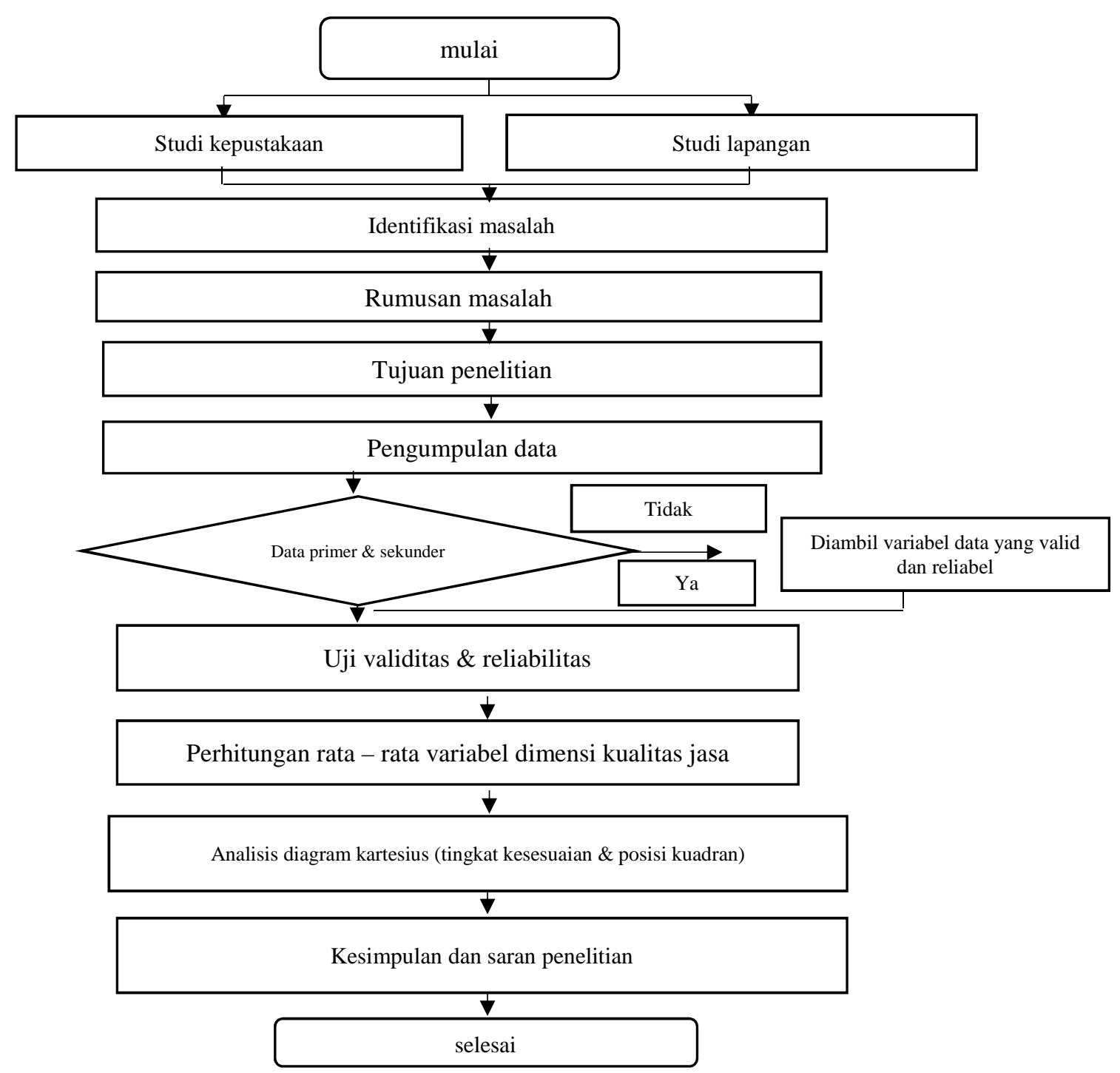




\section{HASIL DAN PEMBAHASAN}

Analisis Gap

Tabel 1 : Perhitungan Rata-rata dan Gap

\begin{tabular}{|c|c|c|c|c|}
\hline PERSEPSI & Rata-rata HASIL & EKSPEKTASI & Rata-rata HASIL & GAP \\
\hline te1 & 3,8125 & tp1 & 3,9625 & $-0,15$ \\
\hline te 2 & 3,775 & tp2 & 3,85 & $-0,075$ \\
\hline te3 & 3,875 & tp3 & 3,8875 & $-0,0125$ \\
\hline te4 & 3,9 & tp4 & 4 & $-0,1$ \\
\hline te5 & 3,5876 & tp5 & 3,6 & $-0,0124$ \\
\hline ee1 & 4,7375 & ep1 & 4,775 & $-0,0375$ \\
\hline ee2 & 4,65 & ep2 & 4,7375 & $-0,0875$ \\
\hline ee3 & 4,6 & ep3 & 4,6125 & $-0,0125$ \\
\hline re1 & 4,4876 & rp1 & 4,575 & $-0,0874$ \\
\hline re2 & 4,725 & rp2 & 4,775 & $-0,05$ \\
\hline re3 & 4,8 & rp3 & 4,8 & $\mathbf{0}$ \\
\hline ae1 & 4,5625 & ap1 & 4,625 & $-0,0625$ \\
\hline ae2 & 4,725 & ap2 & 4,8625 & $-0,1375$ \\
\hline ae3 & 4,8 & ap3 & 4,8375 & $-0,0375$ \\
\hline ree1 & 4,8 & rep1 & 4,8625 & $-0,0625$ \\
\hline ree2 & 4,7125 & rep2 & 4,7625 & $-0,05$ \\
\hline ree3 & 4,75 & rep3 & 4,8125 & $-0,0625$ \\
\hline
\end{tabular}

\section{Analisis Diagram Kartesius}

Analisis gap digunakan untuk menggetahui apakah ada perbedaan antara persepsi responden dengan ekspektasi responden terhadap pelayanan yang diberikan. Uji statistika yang digunakan adalah uji t paired dan diagram kartesius. Uji t paired digunakan untuk menguji apakah ada perbedaan yang signifikan antara persepsi responden dengan ekspektasi responden. Dalam uji t paired ada asumsi yang harus dipenuhi yaitu uji normalitas. Uji normalitas dilakukan dengan menggunakan uji kolmogorov dengan hasil disajikan di bawah ini. 
Tabel 2 : Uji normalitas.

\begin{tabular}{|l|r|r|r|}
\hline \multirow{2}{*}{} & \multicolumn{3}{|c|}{ Kolmogorov-Smirnov $^{\mathrm{a}}$} \\
\cline { 2 - 4 } & Statistic & \multicolumn{1}{c|}{ Df } & \multicolumn{1}{c|}{ Sig. } \\
\hline Persepsi & .266 & 17 & .002 \\
\hline Ekpektasi & .283 & 17 & .001 \\
\hline
\end{tabular}

Nilai sig yang dihasilkan berdasarkan uji kolmogorov sebesar 0.002 untuk persepsi dan 0.001 untuk ekspektasi. Nilai sig dari kedua variabel ini kurang dari 0.05 (5\% tingkat kesalahan penelitian) sehingga dapat disimpulkan data tidak berdistribusi normal. Karena data tidak berdistribusi normal, maka uji t paired digantikan dengan uji Wilcoxon (nonparametric t paired) dengan hasil sebagai berikut.

Tabel 3 : Uji Wilcoxon

\begin{tabular}{|l|r|}
\hline & $\begin{array}{c}\text { Ekpektasi - } \\
\text { Persepsi }\end{array}$ \\
\hline Z & $-3.523^{\mathrm{b}}$ \\
\hline Asymp. Sig. (2-tailed) & .000 \\
\hline \multicolumn{2}{|l|}{ a. Wilcoxon Signed Ranks Test } \\
\hline
\end{tabular}

Nilai sig yang dihasilkan dari uji Wilcoxon sebesar 0.000. Nilai ini lebih kecil dari 0.05 sehingga kesimpulan yang dapat diambil adalah ada perbedaan yang signifikan (gap) antara persepsi responden dengan ekspektasi responden. Dengan kesimpulan yang menyebutkan ada perbedaan yang signifikan antara persepsi responden dengan ekspetaksi responden, maka analisis statistic dilanjutkan dengan analisis diagram kartesius untuk mengetahui variabel yang harus ditingkatkan untuk memenuhi ekspektasi responden.

\section{Gambar 2 : Diagram Kartesius}




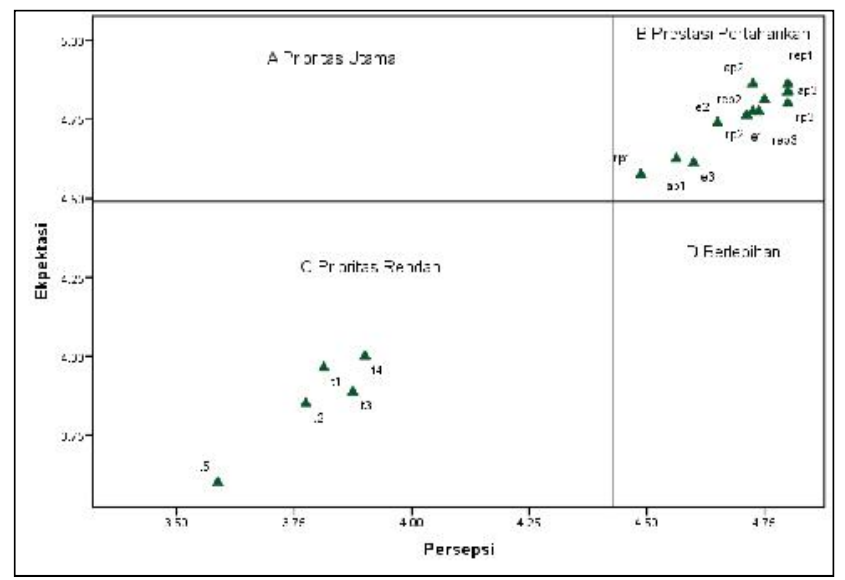

Berdasarkan hasil analisis menggunakan diagram kartesius dapat dilihat bahwa tidak ada yang masuk dalam prioritas utama. Sedangkan indikator yang masuk prioritas rendah yaitu dimensi tangible.

Diagram kartesius digunakan untuk melihat keberadaan dari masing-masing atribut, apabila terletak di kuadran I (prioritas utama yang harus dibenahi, karena harapan tinggi sedangkan persepsi rendah), kuadran II (daerah yang harus dipertahankan karena harapan tinggi dan persepsi juga tinggi), kuadran III (prioritas rendah, karena daerah ini menunjukan harapan rendah dan persepsi rendah), dan kuadran IV (daerah berlebihan, karena harapan rendah namun persepsi tinggi, jadi bukan menjadi prioritas yang dibenahi). Dilihat dari gambar 2 atribut-atribut dalam masing-masing kuadran maka dapat dijelaskan bahwa :

\section{a. Kuadran A.}

Menunjukkan atribut-atribut yang harus dibenahi dan diprioritaskan utama oleh pihak bengkel Warna Indah, karena harapan pelanggan yang tinggi sedangkan persepsi atau yang dirasakan pelanggan rendah.

\section{b. Kuadran D}

Menunjukkan bahwa atribut yang berada pada kuadran ini dianggap kurang penting oleh konsumen (jasa yang diharapkan/ ekspetasi konsumen), namun kinerja kualitas jasa (jasa yang dirasakan ekspetasi) yang diberikan pihak bengkel Cat dan Las Mobil Warna Indah sangat baik/berlebihan. Ini menunjukkan pelayanan yang diberikan pihak bengkel berlebihan dan tidak terlalu diharapkan oleh konsumen. Dari analisis diatas peneliti membuktikan terdapat :

\section{c. Kuadran B}


Menunjukkan atribut-atribut yang harus dipertahankan karena harapan pelanggan tinggi dan persepsi atau yang dirasakan pelanggan juga tinggi. Jadi pihak bengkel Warna Indah telah melaksanakan sesuai dengan harapan pelanggan. Pada kuadran II merupakan penilaian yang seimbang antara pelayanan yang dirasakan/kinerja dengan harapan pelanggan atas pelayanan yang diberikan yaitu pada :

Dimensi Responsiveness pada atribut no. 9" Membantu memberikan informasi tentang layanan bengkel.." dengan penilaian rata-rata presepsi sebesar 4.4875 dan rata-rata ekspetasi sebesar 4.575. Pada atribut no. 10 "Kemudahan administrasi atau pembayaran bagi konsumen" dengan penilaian rata-rata presepsi sebesar 4.725 dan rata-rata ekspetasi sebesar 4.775. Pada atribut no 11 Kecepatan ketepatan perbaikan masalah yang dialami pelanggan dengan penilaian rata-rata persepsi sebesar 4.800 dan rata-rata ekspetasi sebesar 4.800 .

Dimensi Assurance pada atribut no. 12 " Karyawan yang terpercaya." dengan penilaian rata-rata presepsi sebesar 4.562 dan rata-rata ekspetasi sebesar 4.625. Dan pada atribut no. 13 "Adanya jaminan dari produk jasa (pengecatan, las, salon mobil)." dengan penilaian rata-rata presepsi sebesar 4.725 dan rata-rata ekspetasi sebesar 4.862. Pada atribut no 14 Perasaan aman dan nyaman saat melakukan pembayaran layanan bengkel dengan penilaian rata-rata presepsi sebesar 4.8 dan rata-rata ekspetasi sebesar 4.837

Dimensi Emphaty pada atribut no. 6 Waktu beroperasi cocok/nyaman bagi para pelanggan dengan penilaian rata-rata presepsi sebesar 4.737 dan rata-rata ekspetasi sebesar 4.775. Pada atribut no 7 "Penanganan pelanggan dengan prinsip perlakuan yang sama kepada semua pelanggan" dengan penilaian rata-rata presepsi sebesar 4.65 dan rata-rata ekspetasi sebesar 4.737. Pada atribut no 8 "karyawan yang memahami kebutuhan spesifik para konsumen" dengan penilaian rata-rata presepsi sebesar 4.6 dan rata-rata ekspetasi sebesar 4.612.

Dimensi Reliability pada atribut no. 15 "Penyelesaian Jasa layanan bengkel sesuai dengan waktu yang dijanjikan." dengan penilaian rata-rata presepsi sebesar 4.300 dan rata-rata ekspetasi sebesar 4.613; pada atribut no. 16 "Sikap Simpatik dan sanggup menenangkan pelanggan setiap ada masalah" dengan penilaian rata-rata presepsi sebesar 4.8 dan rata-rata ekspetasi sebesar 4.862 ; pada atribut no. 17 "Sistem pencatatan yang akurat dan bebas kesalahan" dengan penilaian rata-rata presepsi sebesar 4.75 dan rata-rata ekspetasi sebesar 4.812 .

\section{d. Kuadran C}


Menunjukkan bahwa atribut yang berada pada kuadran ini, dianggap kurang penting oleh konsumen (jasa yang diharapkan/ ekspetasi konsumen). Sedangkan kinerja kualitas jasa (jasa yang dirasakan/ persepsi konsumen) yang diberikan tergolong cukup. Indikator variabel dimensi yang berada pada kuadran C yang merupakan prioritas rendah dan merupakan prioritas ke empat berdasarkan tingkat kesesuaian ekspektasi dan persepsi (kinerja). Dari analisis diatas peneliti membuktikan terdapat :

Dimensi Tangibles pada atribut no. 1 "Lokasi Bengkel Las \& Cat Mobil Warna Indah." dengan penilaian rata-rata presepsi sebesar 3.812 dan rata-rata ekspetasi sebesar 3.962. Atribut no. 2 "Tampak luar Bengkel (parkir, warna bangunan)." dengan penilaian rata-rata presepsi sebesar 3.775 dan rata-rata ekspetasi sebesar 3.85. Atribut no. 3 "Tampak dalam Bengkel (Luas, teratur penataan alat dan mesin)." dengan penilaian rata-rata presepsi sebesar 3.875 dan rata-rata ekspetasi sebesar 3.887. Dan atribut no. 4 "Fasilitas pendukung layanan (tempat duduk, bacaan, toilet, TV)." dengan penilaian rata-rata presepsi sebesar 3.9 dan rata-rata ekspetasi sebesar 4. Atribut no 5 "Tampilan petugas \& fasilitas operasional (seragam, kerapian, transportasi)" dengan penilaian rata-rata presepsi sebesar 3.587 dan rata-rata ekspetasi sebesar 3.6

\section{KESIMPULAN}

1. Adapun berdasarkan data kuisioner yang diisikan oleh responden (hasil lengkap pada tabel ) berdasarkan hasil perhitungan korelasi product moment dengan menggunakan software SPSS 16 dari masing-masing kualitas layanan terbukti terdapat gap dan gap yang paling tinggi terdapat pada dimensi kualitas layanan indikator T1 (Lokasi Bengkel Las \& Cat Mobil Warna Indah )dimana pada analisa diagram kartesius berada pada kuadran B prioritas rendah sebesar $\mathbf{- 0 , 1 5}$ dimana nilai rata-rata kinerja kualitas jasa (jasa yang dirasakan/persepsi) 3,8125 dan (jasa yang diharapkan/ ekspetasi konsumen) 3,9625.

2. Berdasarkan Data deskriptif konsumen dari 80 responden yang datang ke bengkel cat dan las mobil Warna Indah Kediri setelah dianalisis dengan menggunakan Analisis Diagram Kartesius menunjukkan 4 dimensi pada kuadran B yakni Reliability dengan 3 indikator, Assurance dengan 3 indikator, Assurance dengan 3 indikator dan Responsiveness dengan 3 intikator yang berarti perlu prestasi dipertahankan dan pada kuadran $\mathrm{C}$ ada 1 variabel yakni dimensi Tangible dengan 5 indikator yang berarti perlu mendapatkan perhatian dengan prioritas rendah. 


\section{DAFTAR PUSTAKA}

Arikunto, Suharsimi. 1998. Prosedur Penelitian. Rineka Cipta. Yogyakarta. Emerald. 2009. Service Quality Model A review. http//:www.google.com

Parasuraman, Zeithaml, dn Berry (1985.A Conceptual Model of Service Quality and Its Complication For FutureResearch. The Journal of Marketing

Supranto, J. 1997. Pengukuran Tingkat Kepuasan Pelanggan Untuk Menaikan Pangsa Pasar. Rineka Cipta, Jakarta.

Supriyanto,S. \& Djohan, A. J., 2011. Metodologi Riset Bisnis dan Kesehatan. Banjarmasin: PT. Grafika Wangi Kalimantan.

Yamit, Zulian. 2002. Manajemen Kualitas Produk dan Jasa. Yogyakarta. Ekonisia. 